\title{
Corrosion Performance of as-rolled Mg-8Li-xAl Alloys
}

\author{
Zilong Zhao ${ }^{1,2}$, Yihao Li ${ }^{1,2}$, Yifeng Zhong ${ }^{1,2, *}$, Yiding Liu ${ }^{1,2}$, \\ ${ }^{1}$ School of Civil Engineering, Chongqing University, Chongqing 400045, China \\ ${ }^{2}$ Key Laboratory of New Technology for Construction of Cities in Mountain Area (Chongqing \\ University), Ministry of Education, Chongqing 400045, China \\ *E-mail: zhongjy58@sina.com
}

doi: $10.20964 / 2019.07 .55$

Received: 15 January 2019 / Accepted: 10 May 2019 / Published: 10 June 2019

\begin{abstract}
In this paper, corrosion performance of Mg-8Li-xAl alloys (Mg-8Li, Mg-8Li-2Al, Mg-8Li-3Al, Mg$8 \mathrm{Li}-4 \mathrm{Al}, \mathrm{wt} . \%)$ in different corrosive environments were investigated by means of Scanning electron microscope (SEM), Energy-dispersive X-ray spectroscopy (EDS) and Electrochemical impedance spectroscopy (EIS). The microstructure of alloys were studies before and after the corrosion in the air and the hydrogen evolution performance in $\mathrm{NaCl}$ solution. The influence of elemental $\mathrm{Al}$ on the corrosion resistance of the alloy is revealed. When the $\mathrm{Al}$ content exceeds $3 \%$, the corrosion resistance of Mg-8Li alloy in air can be obviously improved. Meanwhile, the corrosion resistance of the alloy is continuously declining in $\mathrm{NaCl}$ solution with the increase of aluminum content.
\end{abstract}

Keywords: Mg-8Li-xAl alloys, microstructure, hydrogen evolution, corrosion, EIS

\section{FULL TEXT}

(C) 2019 The Authors. Published by ESG (www.electrochemsci.org). This article is an open access article distributed under the terms and conditions of the Creative Commons Attribution license (http://creativecommons.org/licenses/by/4.0/). 